\title{
Güncel Haliyle Bitcoin ve Piyasadaki Değeri Üzerine Bir İnceleme ${ }^{1}$
}

\author{
Özgür GÜVEN*Şahin BULUT**
}

ÖZET

Bitcoin, 2009 yılında ortaya çıkmasıyla devrim niteliğinde bir altyapı sunan kripto para türüdür. Bitcoinin temel teknolojisi olan blokzincir, güvenilir bir üçüncü tarafa ihtiyaç duymayan, merkezi olmayan bir sistem olarak tasarlanmış; geniş uygulama potansiyeli ile kamu ve iş dünyasında hızla kabul görmüştür. Bu çalışmada, Ocak 2012 - Mart 2020 tarihleri arasında cumhuriyet altın1, altın ons fiyat1, ham petrol fiyat1, amerikan doları ve euro para birimleri ile bitcoin arasındaki korelasyon ilişkisi incelenmiştir. Araştırma kapsamında Spearman korelasyon analizinden faydalanılmıştır. Analizlerin sonucuna göre, piyasalara girdiği ilk dönem olan 2012'de bitcoinin diğer göstergelerle arasında istatistiksel olarak anlamlı bir ilişkisi saptanmamıştır ( $p>0.05)$. Bitcoinin dolar karşılı̆̆ının bir önceki yıla göre üç katından fazla arttığı 2017 y1lı ise bitcoinin zirve yılı olup; euro ile arasında pozitif yönlü kuvvetli bir ilişki vardır $(\mathrm{r}=0.873$; $\mathrm{p}<0.001)$. 2012-2020 döneminde istatistiksel olarak bitcoinin ham petrol fiyatı ile arasında negatif yönlü ve zayıf; cumhuriyet altını, altın ons fiyatı, dolar ve euro ile kuvvetli bir ilişki vardır ve bu ilişki anlamlıdır. Yüksek hareketlilik, bitcoinin, istikrarlı bir ödeme aracından ziyade spekülatif bir yatırım aracı olarak görülmesi olarak algılanabilir. Bitcoinin uzun dönemde en çok euro ile arasında kuvvetli bir ilişki olduğu saptanmıştır.

Araştırma Makalesi

Geliş: 10.11 .2020

Kabul: 01.02.2021

Anahtar Kelimeler:

Bitcoin,

Kripto para birimi,

Fintech (Fintek).

\section{Bitcoin Current State and A Study on Bitcoin Value in The Market}

\section{ABSTRACT}

Bitcoin is a type of cryptocurrency that offers a revolutionary infrastructure when it emerged in 2009. The basic technology Blockchain is designed as a decentralized system that does not need a reliable third party; with its wide application potential, it has been rapidly accepted. In this study, the correlation relationship between Cumhuriyet Gold, gold ounce price, crude oil price, american dollar and euro currencies and bitcoin between January 2012 and March 2020 was examined. According to the results of Spearman correlation analysis, a statistically significant relationship was not detected in 2012 ( $p>0.05$ ). The year 2017, was the peak year of bitcoin; a strong positive relationship with the euro $(r=0.873$; $\mathrm{p}<0.001)$. In 2012-2020, the difference between bitcoin and crude oil price was negative and weak; a strong relationship between Cumhuriyet Gold, gold ounce price, dollar and euro, and this relationship is significant. High mobility can be perceived as seeing bitcoin as a speculative investment tool rather than a stable payment instrument. It has been determined that there is a strong relationship between Bitcoin and the euro in the long term.
Research Article

Received: 10.11.2020

Accepted: 02.01.2021

Keywords:

Bitcoin,

Cryptocurrency

Fintech.

* Yüksek Lisans Öğrencisi, Aydın Adnan Menderes Üniversitesi, Sosyal Bilimler Enstitüsü, Ekonomi ve Finans, oguven@adu.edu.tr, ORCID ID: https://orcid.org/0000-0002-7018-9756

** Doç. Dr., Aydın Adnan Menderes Üniversitesi, Ekonomi Anabilim Dalı, sbulut@adu.edu.tr, ORCID ID: https://orcid.org/0000-0002-3462-6381 


\section{GİRiş}

Kripto paralar, merkezi otoriteye ihtiyaç duymayan, dağıtık ve dijital bir para birimi olarak son yıllarda finans dünyasındaki popüler konuların başını çekmektedir.

Kripto para birimleri arasında en popüler ve kullanımı en yaygın olan bitcoin (sembolü B, kısaltması: BTC) olup, yarattığı ilk tetikleyici etki, işlemleri onaylama konusunda hiçbir güvenilir tarafa ihtiyaç duyulmamasından kaynaklanmaktadır. Bitcoinin ilk bloğu olan Genesis Bloğu 3 Ocak 2009 tarihinde oluşturulmuş olup bu tarih tesadüf değildir (BTCTÜRK, 2019). 2008 yılında Yunanistan'da bir sabah halk bankadaki paralarını çekememiş, hiçbir resmi otorite veya banka da açılış tarihi verememiştir (BBC, 2015). 2008 yılında yaşanan bu kriz sadece bu ülkede değildir, global bir kriz söz konusudur; tüm dünyada mevcut ekonomik ve politik sisteme karşı bir güvensizlik hakimdir. Bitcoin, dokuz sayfalık bir makale olarak 31 Ekim 2008'de Satoshi Nakamoto tarafindan White Paper ${ }^{2}$ olarak yayınlanarak dünyaya duyurulmuştur. Hemen ardından Nakamoto'ya ait bitcoin cüzdanına 50 bitcoin transfer edilmesi ile Genesis bloğu üretilmiştir. Satoshi Nakamoto isminin gerçek kişi olup olmadiğ1 bilinmemektedir. Zaman içerisinde "Satoshi Nakamoto" olduğunu iddia eden bazı kişiler olmuş ancak gerçek kişinin kim olduğu veya gerçekte böyle bir kişinin varlığı henüz kanıtlanamamıştır. Bitcoin sistemini icat eden kişi 2011 yılının Nisan ayından sonra ortadan kaybolmuştur (Eğilmez, 2013). Buna rağmen oluşturmuş olduğu sistem matematik prensipleri ve şeffaflığı ile aktif olarak yürütülmeye devam etmektedir (Mancar, 2017).

Kuramsal açıdan bakıldığında sistemin kullanımı karmaşık görünmemektedir. Bu durumda ilk olarak wallet olarak adlandırılan bir cüzdan programı üzerinde yeni bir hesap tanımlanmalıdır. Cüzdan programı, kullanıcının bitcoinlerini tıpkı fiziki bir cüzdandaki gibi saklamakta ve dijital ortamda bu cüzdandaki paralar ile işlem yapılması olanağını sağlamaktadır. Standart bankacılık sistemindeki bir banka hesap cüzdanı gibi işlev gören bu dijital cüzdanlar, kimlik ve adres gibi hiçbir özel bilgiyi içermeyen, rakam ve harflerin bir araya gelmesiyle oluşturulmuş, metin formatında ifade edilen karışı bir dizedir. Hesabı olan herkes bitcoin satın alabilir ve transfer edebilir; bu işlemler belli bir bedel karşılığı olmadan birkaç dakika içinde ve çalışma saati kalıpları dışında olarak 7 gün 24 saat süresince gerçekleştirilebilir. Bitcoin euro, dolar, TL veya başka para birimlerine istenildiği zaman takas edilebilmektedir (Antonopoulos, 2014: 105).

\footnotetext{
${ }^{2}$ White Paper: İlk Para Teklifi'nin (ICO) çözmek istediği bir problemin ana hatlarını, bu sorunun çözümünü, ürünlerinin ayrıntılı bir tanımını, mimarisini ve kullanıcılarla etkileşimini içeren bir belgedir.
} 


\section{Şekil 1. Kâğıt Cüzdan Örneği}

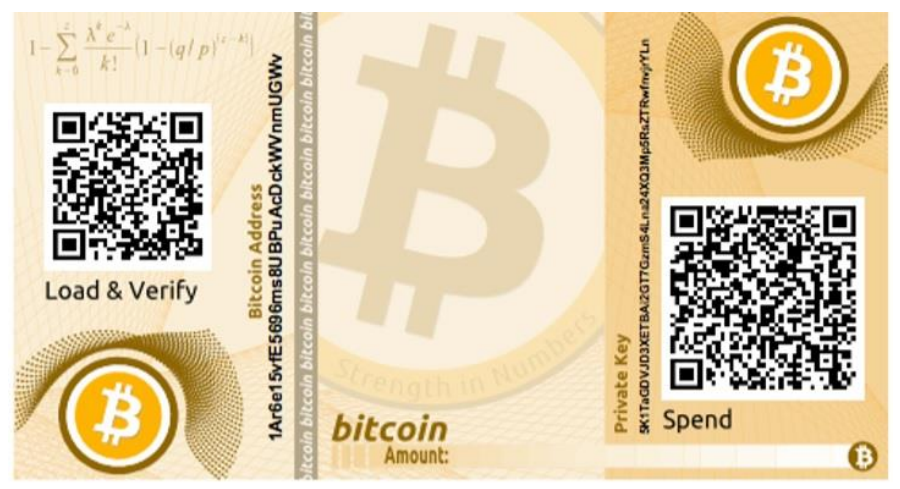

Kaynak: Antonopoulos, 2014: 106

Hızlı ve küresel olduğu gibi şeffaf olması nedeniyle, şayet bir bitcoin cüzdan adresi biliniyorsa, bu hesaba ait bütün bitcoin işlemleri ağdaki dileyen herkes için görünür durumdadır (Çarkacıŏglu, 2016: 12).

\section{GÜNCEL HALIYLE PIYASALARDA BITCOIN}

Bitcoin ile ilk satın alma işleminin gerçekleştirilmesi 22 Mayıs 2010 yılını bulmuştur. Takma adı Laszlo Hanyecz olan bir kullanıcı online olarak Dominos'tan 2 adet pizza satın almış; karşılığında 10.000 BTC ödemiştir (Surda, 2014: 4). Tarihte ilk kez bitcoinin takas aracı olarak kullanılması nedeniyle dünyanın birçok şehrinde 22 Mayıs tarihi “Laszlo'nun Pizza Günü” olarak kutlanmaktadır. Blokzincir tabanlı bitcoinin yapısal özelliklerinden biri de şeffaflığıdır. Bir hesap anahtarının kime ait olduğu herkese açık değildir, ancak ilgili hesap anahtarına ait transfer işlemleri bu şeffaflık özelliği gereği herkese açıktır.

\section{Şekil 2. Son Bitcoin İşlemleri}

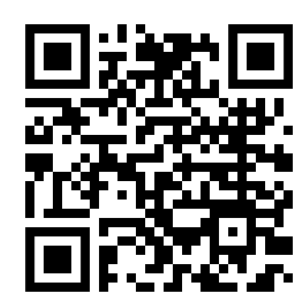

Bitcoine ait son yapılan işlemleri, blokları, bloğun madencisini izlemenin mümkün olduğu bir web sitesi vardır. Şekil 2'de verilen karekod ile bu web sitesine yönlendirme yapılmaktadır. Blockzinciri teknolojisi dağıtık bir veritabanı olarak çalışmakta olup, bitcoin işlemlerinde son blokları ekleyen madencilerin bilgileri bu web sitesinde paylaşılmaktadır.

Tüm zamanların en yüksek bitcoin değeri 17 Aralık 2017 tarihinde 19.524,32\$ olarak tarihe geçmiştir (23.06.2019 itibariyle, kaynak: https://www.blockchain.com/tr/prices). Kripto para piyasas1 
hakimiyeti açısından 26.09.2020 tarihi itibariyle \%58,3 BTC (1 BTC $=\$ 10.723,14), \% 12 \mathrm{ETH}(1 \mathrm{ETH}$ $=\$ 352,20)$ ve $\% 5$ USDT (Tether) (1 USDT $=\$ 1,00)$ ilk üç sırayı almaktadır. Aynı tarihte 1 BTC $=$ 81.752,78€ değerindedir (https://coinmarketcap.com/tr/currencies/bitcoin).

Tablo 1. Karşılaştırmalı Bitcoin Piyasa Değerleri

\begin{tabular}{|c|c|c|c|}
\hline Değerler & 2016 Aralık & 2019 Haziran & 2020 Eylül \\
\hline Piyasadaki Toplam BTC & 16.018 .575 BTC & 17.704 .137 BTC & 18.500 .431 BTC \\
\hline 1 BTC'nin Piyasa Fiyatı & $\$ 752$ & $\$ 10.800,75$ & $\$ 10.723,14$ \\
\hline $\begin{array}{c}\text { Piyasa Değeri } \\
\text { (Market Capitalization) }\end{array}$ & $\$ 12.069 .035 .148$ & $\$ 192.300 .000 .000$ & $\$ 198.382 .628 .430$ \\
\hline \multirow{2}{*}{ Günlük Ticaret Hacmi } & 259.387 BTC & $294.444,39$ BTC & 5.061 .277 BTC \\
\cline { 2 - 4 } & $\$ 195.432 .628$ & $\$ 3.180 .000 .000$ & $\$ 54.272 .761 .192$ \\
\hline
\end{tabular}

Tablo 1'de 2016 yılı Aralık ayı değerleri (Çarkacığlu, 2016: 17), 2019 yılı Haziran ayı değerleri, 2020 yılı Eylül ayı ${ }^{4}$ değerleri kullanılarak piyasadaki yönelim incelenmiştir.

Bir kripto paranın gerçek hayatta kabul görüp kullanımda tercih edilmesi ancak ödeme aracı olarak kullanımının yaygınlaşması ile açıklanabilmektedir. Tablo 1'de verildiği üzere 2016-2020 aralığındaki son 4 yıla ait veriler incelendiğinde, bitcoinin piyasadaki fiyatının yaklaşık 15 kat arttığı, kripto para piyasasındaki değerinin ise 16 kattan fazla arttığı gözlenmiştir.

Türkiye'nin finansal yaklaşımında ise BDDK (Bankacılık Düzenleme ve Denetleme Kurumu) ve SPK (Sermaye Piyasası Kurumu) tarafından yapısı ve çalışma prensibi nedeniyle kripto paralar, kanun kapsamında "elektronik para” şeklinde kabul görmemektedir. TCMB (Türkiye Cumhuriyeti Merkez Bankası) tarafından finansal kararlılık ve süreklilik açısından faydasının incelenmesi amacıyla bitcoin yakından izlenmeye başlanmıştır. Bu amaçla, bahsi geçen bu kurumlar bir araya gelerek kripto paraların temelini oluşturan teknolojiyi ve bu teknolojinin dünyadaki uygulama alanlarını incelemek üzere Blokzincir Çalışma Grubu'nu oluşturduklarını duyurmuştur. TCMB resmî sitesinde 21 Kasım 2018 tarihinde yürürlüğe giren "100 Soruda Merkez Bankacılığı” dokümanında kripto para tanımına (TCMB, 2018: 64) yer vermiştir. Dokümanda, bir varlığın paranın temel fonksiyonlarını ne ölçüde yerine getirdiği kişiden kişiye ve zaman içerisinde değiştiğini belirtmiştir. Bu fonksiyonları yerine getirmesinin, bir varlığın yasal açıdan para olarak nitelendirileceği anlamına gelmediğini ifade etmiştir. Gelecekte bir gün, spekülasyondan uzak ve kararlı kripto paraların piyasada yer alması ve yaygınlığının yüksek olması olanak dışı olmamakla birlikte, günümüz koşulları altında kripto paraların para olarak kabul edilmesini uygun bulmamaktadır. Bu nedenle "kripto para" yerine" kripto varlık" terimi kullanımını önermektedir. Ülkemizde henüz kripto paranın işleyişine dair kanuni bir düzenleme

\footnotetext{
${ }^{3}$ Veriler http://www.blockchain.info/charts adresinden 20 Haziran 2019 tarihinde temin edilmiştir.

${ }^{4}$ Veriler https://coinmarketcap.com/ adresinden 03 Eylül 2020 tarihinde temin edilmiştir.
} 
yürürlükte değildir. Dönemin başbakan yardımcısı tarafından bitcoin finans tarihinin en büyük balonu olarak tanımlanmış, fiyatının birdenbire dibe vuracağı ve ardından yine birdenbire yükselişe geçebileceği gibi tutarsızlıklar göz önüne alındığında, en doğrusunun bitcoine mesafeli kalınması olduğu belirtilmiştir (Alptekin, 2017: 11).

Haziran 2019'da 4 olan Türkiye'deki kripto para ATM sayısı, Aralık 2019 tarihi itibariyle 10, Eylül 2020 tarihi itibariyle ise 2 olup tümü İstanbul'da bulunmaktadır (Coinatmradar, 26 Eylül 2020). ATM'lerde başta BTC olmak üzere BCH, ETH, LTC ve DASH türü kripto paralar işlem görmektedir.

Dilek (2018: 17) verilerinin günümüz verileri ile karşılaştırması aşağıdaki tabloda yer almakta olup kripto para yayılımının global gidişatı konusunda 2018-2020 aralığında son iki yılın değerleri izlenmektedir:

Tablo 2. Kripto Para ATM'lerinin Artışı

\begin{tabular}{|c|c|c|c|c|}
\hline Tarih & Ülke Sayısı & ATM Sayısı & İşletme Sayısı & İlk 3 Ülke \\
\hline Aralık 2017 & 61 & 1.963 & $>11.000$ & ABD, Kanada, Birleşik Krallık \\
\hline Aralık 2019 & 75 & 6.217 & 148.884 & ABD, Kanada, Birleşik Krallık \\
\hline Eylüı 2020 & 71 & 10.348 & 212.279 & $\begin{array}{c}\text { ABD (8.202), Kanada (891), Birleşik } \\
\text { Krallık (275) }\end{array}$ \\
\hline
\end{tabular}

Kaynak: https://coinatmradar.com, Eylül 2020

Gün geçtikçe daha çok ilgi çeken Blockchain teknolojisinin en önemli kullanım alanı, kripto paralar ve özellikle bitcoin sayesinde "finans" olmuştur. 2020 yılı Eylül ayı itibariyle dünya genelinde 3.487 tür kripto para çeşidi olduğu bilinmektedir. Kripto paraların güncel piyasa değeri 341,91 milyon dolar olup 198.356.681.456 dolara yaklaşan piyasa değeri ile bitcoin bu dağılımın çok önemli bir kısmını oluşturmaktadır (https://coinmarketcap.com/, 26 Eylül 2020). Bu haliyle BTC'nin piyasa hâkimiyeti $\% 58,3$ 'tür.

Tablo 3. Piyasa Değerine Göre En İyi 5 Kripto Para Birimi

\begin{tabular}{|c|c|c|c|c|}
\hline Sira No & Kripto Para Birimi & Piyasa Kapitalizasyonu & Güncel Değer & İşlem Hacmi (24 saat) \\
\hline 1 & B Bitcoin & $\$ 198.382 .628 .430$ & $\$ 10.723,14$ & $\$ 54.272 .761 .192$ \\
\hline 2 & $\vartheta$ Ethereum & $\$ 39.715 .036 .503$ & $\$ 352,20$ & $\$ 13.771 .994 .180$ \\
\hline 3 & F Tether & $\$ 15.291 .484 .408$ & $\$ 1,00$ & $\$ 38.596 .471 .655$ \\
\hline 4 & $\asymp_{\mathrm{XRP}}$ & $\$ 10.843 .112 .950$ & $\$ 0,240438$ & $\$ 1.723 .340 .911$ \\
\hline 5 & 【B] Bitcoin Cash & $\$ 3.984 .181 .457$ & $\$ 215,03$ & $\$ 1.246 .916 .539$ \\
\hline
\end{tabular}

Kaynak: https://coinmarketcap.com, 26 Eylül 2020 


\section{ÇALIŞMANIN VERI SETI VE YÖNTEMI}

Çalışmada bitcoinin yatırım amaçlı kullanımını incelemek üzere 2012-2020 dönemindeki hareketliliği gözlenmiştir. Çalışmada bitcoinin ekonomik gösterge olarak cumhuriyet altını, altın ons fiyatı, ham petrol fiyatı, amerikan doları ve euro ile arasındaki istatistiksel ilişki incelenmiştir. Verilen bu değişkenler arasında olumlu ya da olumsuz bir doğrusal ilişkinin varlığını tespit etmek ve değerlendirmek amaçlanmıştır.

Çalışmada kullanılan veri setinin frekansı aylıktır. Dönem analizi için zaman aralığı Ocak 2012 ile Mart 2020 arası dönemi kapsamaktadır. Çalışmada kullanılan değişkenler aşağıda verilmiştir:

1. Bitcoin: Kripto para birimi olarak sektörün lideri bitcoin seçilmiştir.

2. Cumhuriyet altını: Darphane tarafindan basılan bu altının, halk arasında "yastık altı" tabiri ile ifade edilmiş haliyle fiziki yapıda saklanması yaygındır. Finans sektöründeki dijitalleşmenin yatırımcılara sunduğu avantaj sayesinde elektronik ortamda tasarrufu da mümkün olan Cumhuriyet altını uygulamaya dahil edilmiştir.

3. Altın ons fiyatı: Sınırlı sayıda olması altına ekonomik bir değer biçmiş olup, her koşulda satınalma gücünü koruyabilmesi, değer saklama aracı olarak tüm dünyada kabul görmesi, siyasi ve ekonomik belirsizlik ortamında güvenilir liman olması nedeniyle altın stratejik önem taşımaktadır (Vural, 2003, i).

4. Ham petrol: Endüstriyel kullanım alanı geniş olan petrol, kayda değer bir üretim ve yatırım ürünü olup finans piyasalarında siyah altın olarak da bilinmektedir. Önemli bir hammadde oluşunun yanı sıra yatırım aracı olarak da piyasada bulunan petrol bu araştırmaya dahil edilmiştir.

5. Amerikan doları: Dünyada çapında ekonomik ve politik gelişmeler ve alınan kararlar nedeniyle değeri dalgalı bir özellik gösteren dolar, yatırımcılar tarafından en çok tercih edilen yatırım araçlarından birisidir. Rezerv para olması, küresel çapta varlık fiyatlandırmasında tercih edilmesinden dolayı seçilmiştir.

6. Euro: Euro Bölgesi'nde yaşanan ekonomik çalkantılara rağmen değerini koruması, Türkiye'nin dış ticaretinde en büyük payı AB üyesi ülkelerin alması (Türkiye İstatistik Kurumu, 2020), yatırımcılar tarafından en fazla tercih edilen döviz türlerinden birisi olması nedeniyle seçilmiştir.

Korelasyon analizi, iki değişkene ait gözlem verilerinin birbirleriyle arasındaki değişim şeklini araştırmaktadır. İki değişkenin birlikte değişme derecesini ölçmek amacıyla hesaplanan korelasyon katsayısına korelasyon katsayısı denilmekte ve " $r$ " ile gösterilmektedir. Korelasyon katsayısı r değerlendirilirken, şayet $r$ değeri 0-0.49 arasında ise korelasyon zayıf, 0.5-0.74 arasında ise orta 
derecede, 0.75-1 arasında ise kuvvetli ilişki vardır olarak yorumlanmaktadır (Bulut, 2013: 145-146). Çalışmada, kullanımı yaygın olan Spearman korelasyon katsayısı analizi tercih edilmiştir.

\section{İNCELEME BULGULARI}

Yapılan uygulamada, bitcoinin takas ve yatırım aracı olarak kendini göstermeye başladığı 2012 yılı baz alınmıştır. Ocak 2012 itibariyle $1 \mathrm{BTC}=5,59$ \$'dır.

Her yıla ait değişkenler arası korelasyonları içeren tablolar ardarda sıralanmış ve değerlendirilmiştir. 2012 yılına ait tabloda Bitcoinin ekonomik göstergelerle arasında istatistiksel olarak anlamlı bir ilişkisi saptanmamıştır ( $>>0.05)$. Bitcoinin zirve yaptığ 2017 yılına ait korelasyon tablosunda ise Euro ile arasında pozitif yönlü kuvvetli bir ilişki tespit edilmiştir $(r=0.873 ; p<0.001)$.

Tablo 4. Korelasyon Tablosu: Ocak 2012 - Mart 2020

\begin{tabular}{|c|c|c|c|c|c|c|c|}
\hline \multicolumn{2}{|r|}{ Değişken } & Bitcoin & $\begin{array}{c}\text { Cumhuriyet } \\
\text { Altını }\end{array}$ & $\begin{array}{l}\text { Altın } \\
\text { Ons }\end{array}$ & $\begin{array}{l}\text { Ham } \\
\text { Petrol }\end{array}$ & $\begin{array}{c}\text { Amerikan } \\
\text { Dolar1 }\end{array}$ & Euro \\
\hline \multirow{3}{*}{ Bitcoin } & Korelasyon Katsayısı & 1,000 &, $784 * *$ &, $787 * *$ &,$- 336 * *$ &, $898 * *$ &, $921 * *$ \\
\hline & Anlamlilık (p) & . &, 000 &, 000 &, 001 &, 000 &, 000 \\
\hline & Gözlem Sayısı & 99 & 99 & 99 & 99 & 99 & 99 \\
\hline \multirow{3}{*}{$\begin{array}{c}\text { Cumhuriyet } \\
\text { Altını }\end{array}$} & Korelasyon Katsayısı & ,784** & 1,000 & ,999** &,$- 519 * *$ & ,904** &, $896 * *$ \\
\hline & Anlamlılık (p) & , 000 & . &, 000 &, 000 &, 000 &, 000 \\
\hline & Gözlem Sayısı & 99 & 99 & 99 & 99 & 99 & 99 \\
\hline \multirow{3}{*}{ Altın Ons } & Korelasyon Katsayısı & ,787** & ,999** & 1,000 &,$- 526 * *$ &, $909 * *$ & ,900** \\
\hline & Anlamlılık (p) &, 000 &, 000 &. &, 000 &, 000 &, 000 \\
\hline & Gözlem Sayısı & 99 & 99 & 99 & 99 & 99 & 99 \\
\hline \multirow{3}{*}{ Ham Petrol } & Korelasyon Katsayısı &,$- 336 * *$ &,$- 519 * *$ &,$- 526 * *$ & 1,000 &,$- 555^{* * *}$ &,$- 491 * *$ \\
\hline & Anlamlilık (p) &, 001 &, 000 &, 000 &. &, 000 &, 000 \\
\hline & Gözlem Sayısı & 99 & 99 & 99 & 99 & 99 & 99 \\
\hline \multirow{3}{*}{$\begin{array}{c}\text { Amerikan } \\
\text { Doları }\end{array}$} & Korelasyon Katsayısı &, $898 * *$ & ,904** & ,909** &,$- 555 * *$ & 1,000 &, $984 * *$ \\
\hline & Anlamlilik (p) &, 000 &, 000 &, 000 &, 000 & . &, 000 \\
\hline & Gözlem Sayısı & 99 & 99 & 99 & 99 & 99 & 99 \\
\hline \multirow{3}{*}{ Euro } & Korelasyon Katsayısı & ,921** &, $896 * *$ &, $900 * *$ &,$- 491 * *$ & ,984** & 1,000 \\
\hline & Anlamlilık (p) &, 000 &, 000 &, 000 &, 001 &, 000 & . \\
\hline & Gözlem Sayısı & 99 & 99 & 99 & 99 & 99 & 99 \\
\hline
\end{tabular}

Bitcoinin cumhuriyet altını, külçe altın, dolar ve euro ile arasında kuvvetli bir ilişki vardır ve bu ilişki anlamlidır.

Ancak ham petrol fiyatı ile negatif yönlü ve zayıf bir ilişkisi olduğu saptanmıştır. 


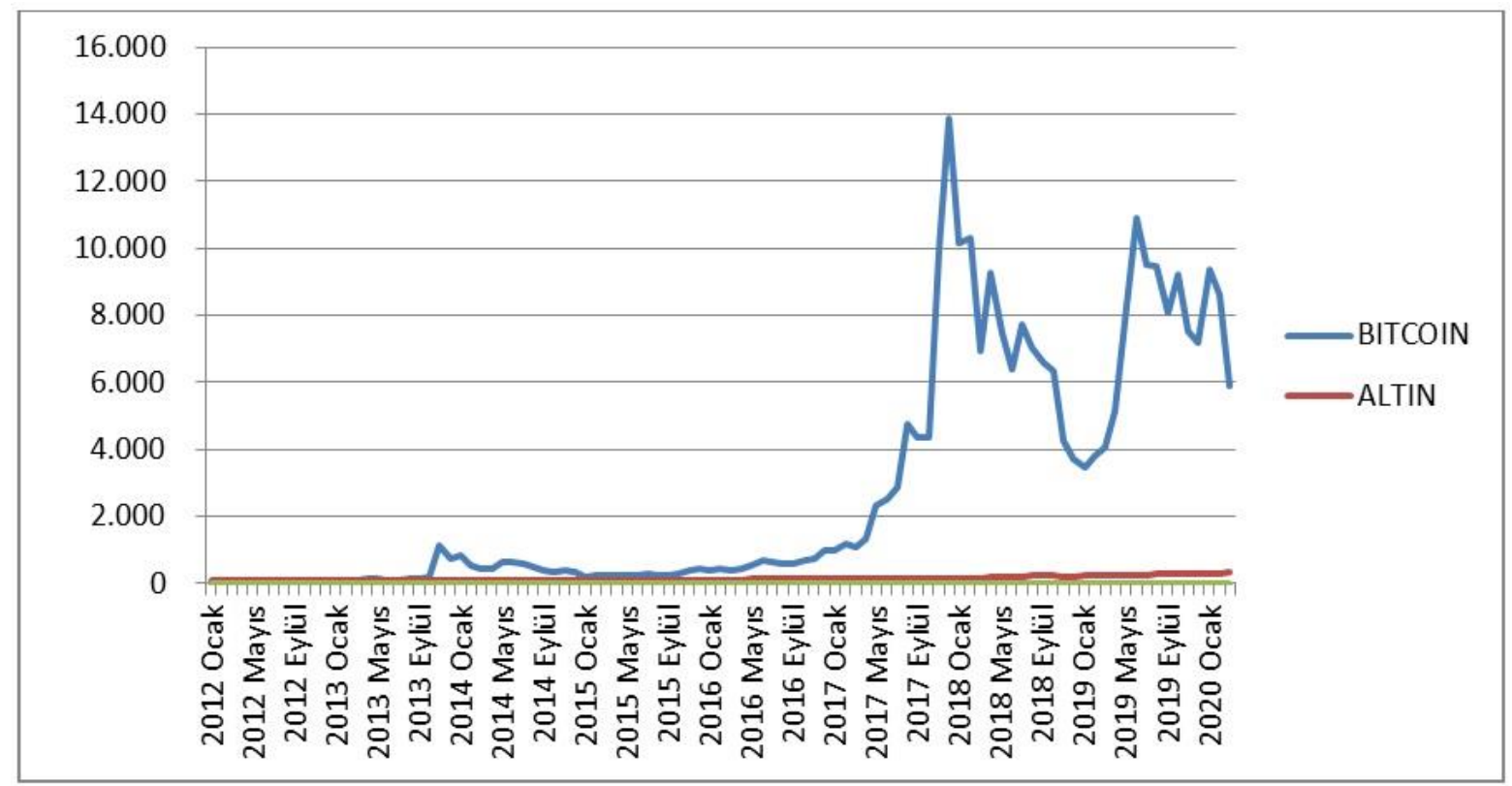

Şekil 3'de 2012-2020 döneminde bir yatırımcının BTC ve altın olarak tasarruf etmesi durumunu gösteren grafik yer almaktadır. Grafik incelendiğinde 2017 yılına kadar bitcoin kurunda fiyat seyrinin çok dalgalı olmadığı görülmektedir. Bitcoinin dolar karşılığının bir önceki yıla göre 3 katından fazla artmasıyla, 2017 yılı bitcoinin zirve yılı olarak kayda geçmiştir.

\section{SONUÇ}

Finans sektöründe işlemlerin gerçekleşmesi güven çerçevesinde sağlanmaktadır. Geleneksel yöntemlerde işlemler aracı kurumlar tarafından güvence altına alınmaktadır. 2008 yılında küresel bir kriz yaşanmış, mevcut ekonomik ve politik sisteme karşı bir güvensizlik ortama hakim olmuştur. Finansal kurumlara olan güvenin sarsıldığı bu kriz ortamında Nakamoto tarafindan Blokzincir teknolojisi yayımlanmıştır. Blokzincir teknolojisi ardında bıraktığı 10 yıla rağmen popülerliğini kaybetmeyerek; son yıllarda yenilikçi teknoloji uzmanlarından ve hükümetlerden artan bir ilgi görmektedir.

Bu çalışmada, Blokzincir teknolojisini kullanan kripto para türleri arasında popüler olan ve kripto para piyasasının \% 58,3'ünü elinde tutan bitcoinin ekonomideki yeri incelenmiştir. Önceki yıllarda yapılmış çalışmalardaki veriler ile güncel piyasa hacmi karşılaştırılmıştır. Bitcoin değerinin artan bir trendde olduğu gözlenmiştir.

Çalışmada, Ocak 2012 - Mart 2020 tarihleri arasında cumhuriyet altını, altın ons fiyatı, ham petrol fiyatı, amerikan doları ve euro para birimleri ile bitcoin arasındaki istatistiksel ilişkisi araştırılmıştır Araştırma kapsamında analizlerde IBM SPSS Statistics 25 programından faydalanılmış, Spearman korelasyon katsayısı analizi kullanılmıştır. Yapılan analizlerinin sonucuna göre piyasalarda yer 
edinmeye başladığı ilk dönem olan 2012'de bitcoinin diğer göstergelerle arasında istatistiksel olarak anlamlı bir ilişkisi saptanmamıştır ( $>00.05)$. Bitcoinin dolar karşılığının bir önceki yıla göre üç katından fazla arttığ 2017 yılı ise bitcoinin zirve yılı olup; euro ile arasında pozitif yönlü kuvvetli bir ilişki tespit edilmiştir $(r=0.873$; $\mathrm{p}<0.001)$. 2012-2020 döneminde istatistiksel olarak bitcoinin ham petrol fiyatı ile arasında negatif yönlü ve zayıf; cumhuriyet altını, altın ons fiyatı, dolar ve euro ile arasında ise kuvvetli bir ilişki var olduğu ve bu ilişkinin anlamlı olduğu saptanmıştır. Yüksek hareketlilik, bitcoinin, istikrarlı bir ödeme aracından ziyade spekülatif bir yatırım aracı olarak görülmesi olarak algılanabilir. Bitcoinin uzun dönemde en çok euro ile arasında kuvvetli bir ilişki olduğu saptanmıştır.

Türkiye'de bitcoin alımsatım işlemleri gerçekleşmesine rağmen, bir çok ülkede olduğu gibi, ilgili otoriteler tarafından uzaktan izlenmektedir. Henüz bir bitcoin borsası ülkemizde kurulmamıştır. Bitcoin kullanımını destekleyen düzenlemelerin olası riskler değerlendirilerek hayata geçirilmesiyle bu pazardan pay alınması ve gelir elde edilmesi mümkün görülmektedir. 


\section{KAYNAKÇA}

Alptekin, E. (2017). Blokzincir ve Kripto Paralar, Dünya Ekonomisini Dönüştürüyor. İzmir Ticaret Odası AR\&GE Bülten, 2017 Kasım Aralık. http://izto.org.tr/demo_betanix/uploads/cms/yonetim.ieu.edu.tr/6417_1514355987 .PDF adresinden alınmıştır, s. 11.

Antonopoulos, M. A. (2014). Mastering Bitcoin - Unlocking Digital Currencies. O'Reilly Media.

BBC (2015).

https://www.bbc.com/turkce/ekonomi/2015/06/150628_yunanistan_banka_kapali adresinden alınmıştır.

BTCTÜRK (2019). 10 Yılda Bitcoin. https://www.btcturk.com/yardim/10-yilda-bitcoin adresinden alınmıştır.

Bulut, Ş. (2013). Türkiye'de Seçilmiş Makroekonomik Değişkenler ile İstanbul Menkul Kıymetler Borsası (İMKB) Arasındaki İlişki. Doktora Tezi, Adnan Menderes Üniversitesi, Sosyal Bilimler Enstitüsü, Aydın.

Çarkacıoğlu, A. (2016). Kripto-Para Bitcoin. Sermaye Piyasası Kurulu Araştırma Raporu, Ankara.

Dilek, Ş. (2018). Blokzincir Teknolojisi ve Bitcoin. Analiz, Şubat 2018, S. 231, SETA Yayınları, Ankara.

Eğilmez, M. (2013). Kendime Yazılar: Bitcoin.

http://www.mahfiegilmez.com/2013/11/bitcoin.html adresinden alınmıştır.

Mancar, B. (2017). Bitcoin Hakkında Bilmeniz Gereken 9 Önemli Bilgi. http://www.webmasto.com/Bitcoin-hakkinda-bilmeniz-gereken-9-onemli-bilgi adresinden alınmıştır.

Surda, P. (2014). The Origin, Classification And Utility of Bitcoin. https://papers.ssrn.com/sol3/papers.cfm?abstract_id=2436823, s. 4.

TCMB (2018). 100 Soruda Merkez Bankacılığı. https://www.tcmb.gov.tr/wps/wcm/connect/2d9f2c1d-18eb-4124-8fd9a4ea189a24ad/100+Soruda+TCMB+web.pdf?MOD=AJPERES\&CVID=\&CACH $\mathrm{E}=\mathrm{NONE} \& \mathrm{CONTENTCACHE}=\mathrm{NONE}$ adresinden alınmıştır, s. 64-69.

Türkiye İstatistik Kurumu (2020). Tablo 5: Ülke Gruplarına Göre D1ş Ticaret. https://data.tuik.gov.tr/Bulten/Index?p=Dis-Ticaret-Istatistikleri-Ekim-202033858 adresinden alınmıştır.

Vural, M. G. (2003). Altın Piyasası ve Altın Fiyatlarını Etkileyen Faktörler. Uzmanlık Yeterlilik Tezi, Türkiye Cumhuriyeti Merkez Bankası, Ankara. 